IRA-International Journal of Applied Sciences ISSN 2455-4499; Vol.04, Issue 01 (2016)

Institute of Research Advances

http://research-advances.org/index.php/IRAJAS

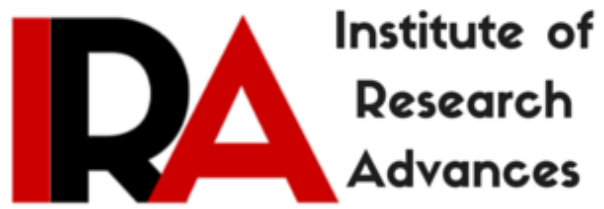

\title{
Treating Blast and Explosion Victims: An Overview
}

\author{
Surgeon Commander Chandrasekhar Krishnamurti, M.D. \\ Associate Professor, NRI Institute of Medical Sciences, \\ Sangivalasa, Visakhapatnam-531162, A.P., India.
}

DOI: http://dx.doi.org/10.21013/jas.v4.n1.p18

\section{How to cite this paper:}

Krishnamurti, C. (2016). Treating Blast and Explosion Victims: An Overview. IRAInternational Journal of Applied Sciences (ISSN 2455-4499), 4(1). doi:http://dx.doi.org/10.21013/jas.v4.n1.p18

(C) Institute of Research Advances (cc) BY-NC

This works is licensed under a Creative Commons Attribution-Non Commercial 4.0 International License subject to proper citation to the publication source of the work.

Disclaimer: The scholarly papers as reviewed and published by the Institute of Research Advances (IRA) are the views and opinions of their respective authors and are not the views or opinions of the IRA. The IRA disclaims of any harm or loss caused due to the published content to any party. 


\section{$\underline{\text { INTRODUCTION }}$}

Blast injuries result from explosions that have the capability to cause multisystem, life-threatening injuries in single or multiple victims simultaneously. The injury patterns following such events are a product of the composition and amount of the materials involved, the surrounding environment, delivery method (if a bomb), the distance between the victim and the blast, and any intervening protective barriers or environmental hazards. These types of events present complex triage, diagnostic, and management challenges for the health care provider.

\section{THE PHYSICS OF INJURIES}

An explosion is defined as a rapid release of energy and its magnitude depends upon on the type of explosive detonated, the space in which the blast occurs and the degree of confinement of the explosion.

The explosive pressure that accompanies the bursting of bombs and shells ruptures their casing and imparts high velocity to the resulting fragments. These can cause more devastating injuries to tissues than bullets. High-order explosives (HEs) undergo detonation, an almost instantaneous transformation of the original explosive material into gases occupying the same volume of space under extremely high pressure. These high-pressure gases rapidly expand, compress the surrounding medium, and produce a defining supersonic, overpressurization blast wave. Examples of HEs include materials such as TNT, ammonium nitrate fuel oil, dynamite, and C-4 "plastic" explosives. In general, only HE explosions produce severe primary blast injury. $\mathrm{C} 4$ explosions can create initial pressures of over 4 million pounds per square inch $(30 \mathrm{GPa})$.

Low-order explosives (LEs) are composed of propellants, such as black powder, and pyrotechnics, such as fireworks. LEs undergo deflagration rather than detonation and release energy relatively slowly compared with HEs. This results in a subsonic explosion lacking the over pressurization blast wave that characterizes HEs. Although LE explosions can be deadly, LE explosions very uncommonly cause the pulmonary and central nervous system injuries unique to primary blast injury. Industrial accidents and terrorist explosions may be associated with the release of toxic and/or radioactive materials. (1)

All explosives are accompanied by a complex blast wave having two components, a blast pressure wave (dynamic overpressure) with a positive and negative phase and another mass movement of air (blast wind). The HE "blast wave" (over-pressure component) should be distinguished from "blast wind" (forced super-heated air flow). The latter may be encountered with both HE and LE. The blast pressure wave travels at the speed of sound and flows over and around obstructions and can have devastating effects on the human body. The blast wind is supersonic, disrupts the environment and buildings, hurling debris and people. The leading edge of a blast wave is called the blast front. When a blast front reaches a victim, it causes an enormous, almost instantaneous rise in ambient pressure. Because explosive gases continue to expand from their point of origin, a longer negative under pressure (relative vacuum) follows the peak positive overpressure. 


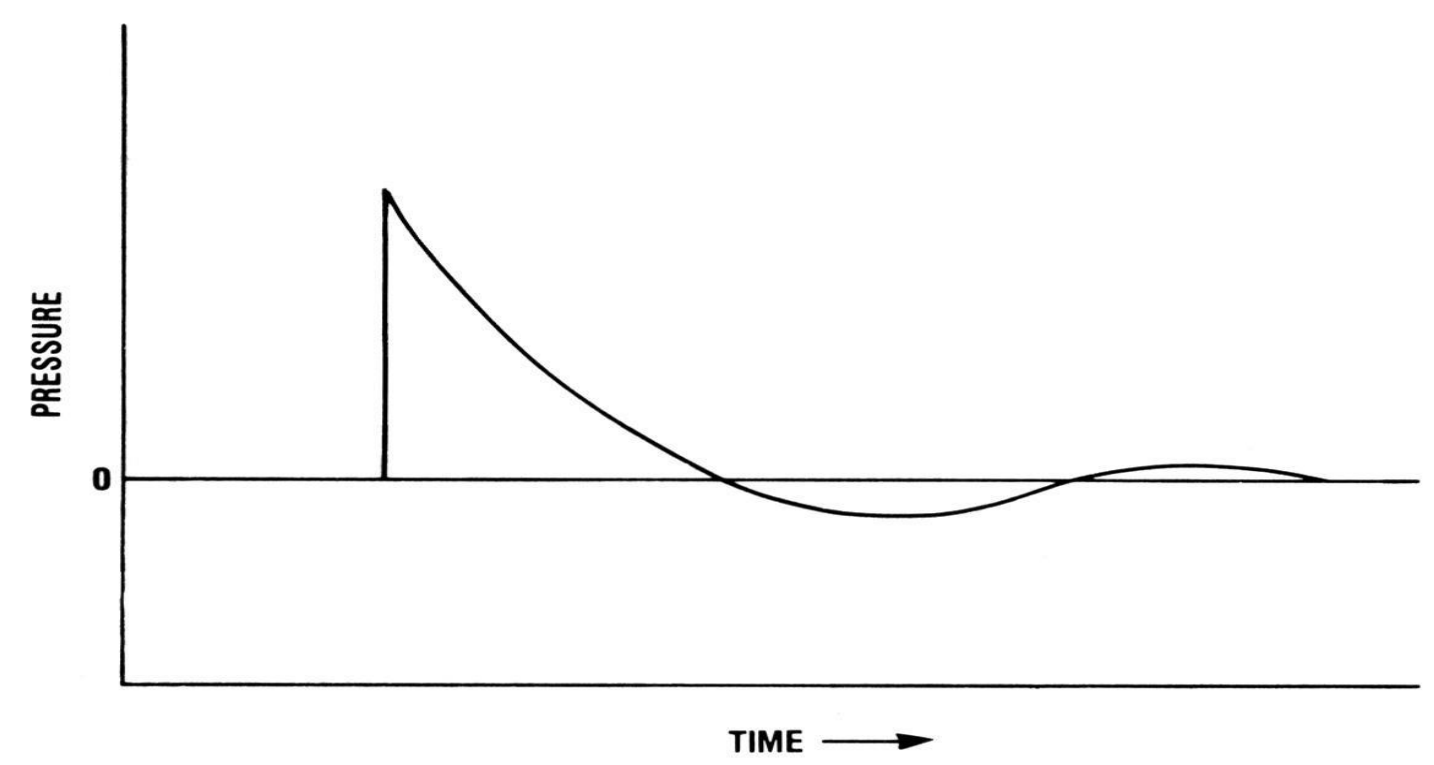

Fig 1: Blast injuries. Idealized graph of a blast pressure wave over time. Courtesy of Bowen TE and Bellamy RF, eds, Emergency War Surgery. Washington, DC: United States Government Printing Office, 1988.

Most of the damage is done as a result of the shock wave that is generated outwards in all directions at speeds in excess of $3 \mathrm{~km} / \mathrm{sec}$ creating two types of pressures. The first is the overpressure i.e. pressure increase over the normal atmospheric pressure and surrounds the object as the shock wave hits it and crushes it inwards. Next, the dynamic pressure strikes each object like a wind force, with the shock wave, moving objects outwards, toppling and tearing them apart. A high pressure wave will have a force of at least 40 kilopascal [kPa] or 6 psi. An overpressure of $100 \mathrm{kPa}(15 \mathrm{psi})$ is considered to be the threshold for lung injury. Most injuries are usually directly proportional to the distance from the point of detonation. Intensity of an explosion pressure wave declines with the cubed root of the distance from the explosion. A person $3 \mathrm{~m}$ (10 ft) from an explosion experiences 9 times more overpressure than a person 6 $\mathrm{m}(20 \mathrm{ft})$ away. Blast waves are reflected by solid surfaces; thus, a person standing next to a wall may suffer increased primary blast injury. (2) 


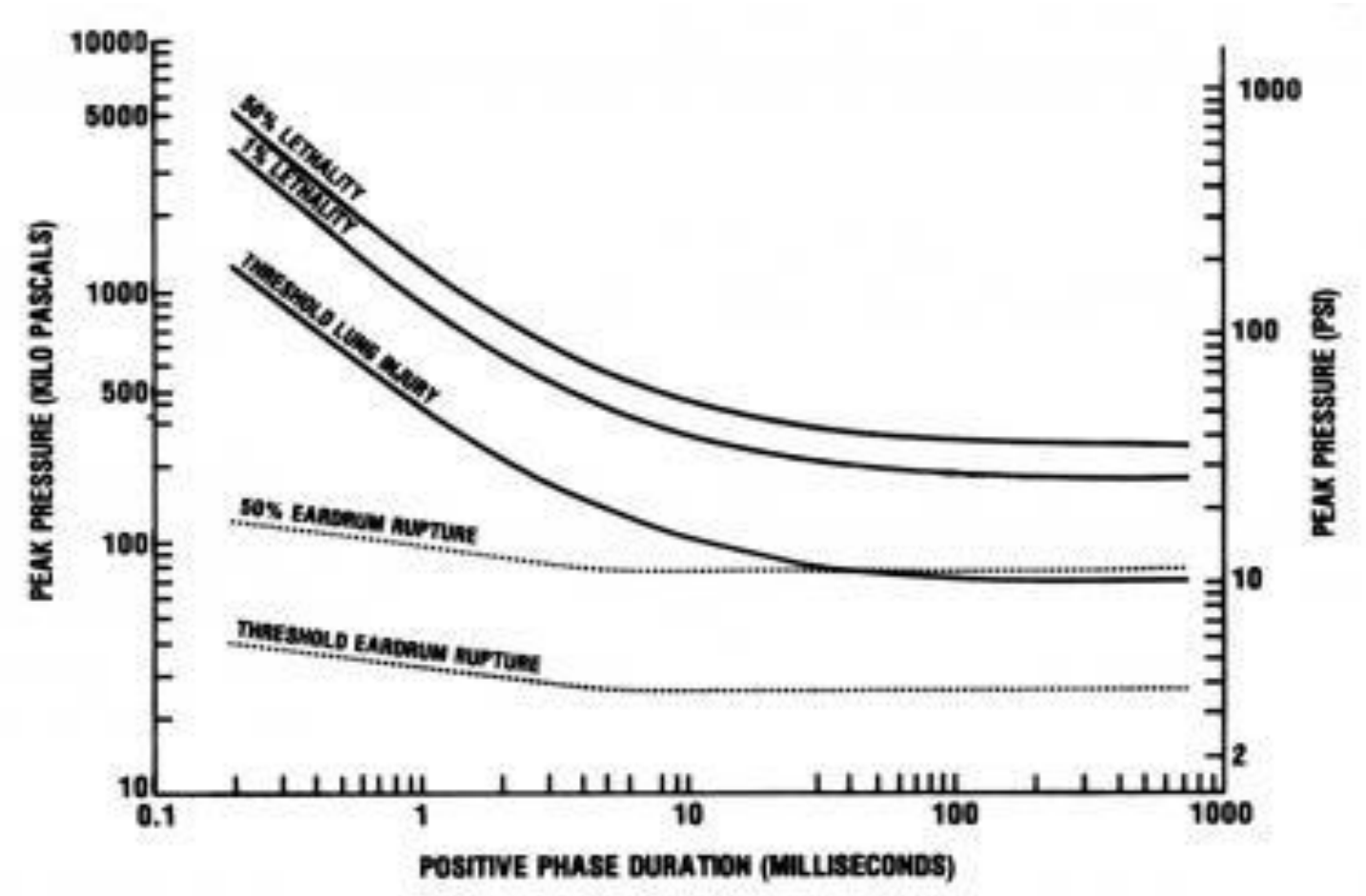

Fig 2: Blast injuries. Estimated human tolerances for single, sharp, rising blast waves.

Courtesy of Bowen TE and Bellamy RF, eds, Emergency War Surgery. Washington, DC: United States Government Printing Office, 1988.

\section{BLAST INJURIES}

Blast injuries are generally categorized as primary to quaternary.

- Primary injuries : Unique to high order explosives(HE), caused solely by the direct effect of transmitted blast overpressure waves on gas-containing tissues like lungs GIT and middle ear and also cerebral concussion.

- Secondary injuries : caused by flying objects and airborne debris striking people. Results in penetrating ballistic (fragmentation)injuries of any part of the body

- Tertiary: caused by high-energy explosions; occuring very close to the explosion source. When victim's entire body is transposed by the force of the blast wind and strikes other objects to result in skull(closed and open brain injuries) and long bone fractures. Injuries due to structural collapse also fall in this category.

- Quaternary: encompass all other injuries caused by explosions like burns (chemical or thermal); injury from falling objects; crush injuries from collapsed structures and displaced heavy objects; falls resulting from the explosion; and toxic dust, gas, or radiation exposure.

- Low order explosives (LE) create subsonic explosions and their effects are classified differently because they lack the self-defining HE over-pressurization wave. LE's mechanisms of injuries are characterized as due from ballistics (fragmentation), blast wind (not blast wave), and thermal. There is some overlap between LE descriptive mechanisms and HE's Secondary, Tertiary, and Quaternary mechanisms.

- Terrorists use illegally obtained manufactured weapons or improvised explosive devices (also known as "IEDs") that may be composed of HE, LE, or both. Manufactured and improvised bombs cause markedly different injuries. 
Acute methemoglobinemia has been reported after nitroglycerine transcutaneous absorption resulting from a bomb explosion. $(3,4,5)$

The primary blast wave can cause perforation of the tympanic membrane, hemotympanum without perforation, ossicle fracture or dislocation, injuries to the lungs and bowel. (6) The blast wind can cause serious penetrating injuries resulting in $n$ deafness, post blast respiratory insufficiency (PBRI) consequent to pulmonary contusion and perforations of the stomach, small intestine and caecum. The eyes must also be carefully examined for distortion of iris, hyphema and blast energized debris or fragments . Typical injuries include ruptured internal organs, lung contusions, burns, lacerations, impaled objects, fractures and crushing injuries. Explosions often produce superheated air that can cause thermal burns of the surface as well as of the respiratory system. Most bomb-related burns cover $<20 \%$ of the total body surface area (TBSA), but occur in combination with other blast injuries. (7)

Blast shock waves travel more rapidly through liquid media. Hence injuries sustained from a blast when immersed in water cause more severe deafness, post blast respiratory insufficiency (PBRI) consequent to pulmonary contusion and perforations of the stomach, small intestine and caecum. The eyes must also be carefully examined for distortion of iris, hyphema and blast energized debris or fragments. Blast victims will also frequently have thermal burns and inhalation of toxic gases and smoke

\section{INHALATIONAL INJURY AND LUNG BAROTRAUMA}

"Blast lung" is a direct consequence of the HE over-pressurization wave. It is the most common fatal primary blast injury among initial survivors. Signs of blast lung are usually present at the time of initial evaluation, but they have been reported as late as 48 hours after the explosion. Blast lung is characterized by the clinical triad of apnea, bradycardia, and hypotension. Pulmonary injuries vary from scattered petechae to confluent hemorrhages. Blast lung should be suspected for anyone with dyspnea, cough, hemoptysis, or chest pain following blast exposure. Blast lung produces a characteristic "butterfly" pattern on chest X-ray.

Exposure to fire and smoke is a common occurrence in conflagarations and may require emergency respiratory care. Inhalation injury is relatively common (18\%) among those who survive explosions in confined spaces. Events such as carbon monoxide poisoning, chemical tracheobronchitis caused by inhalation of incomplete products of combustion and toxic fumes, as well as the direct effect of thermal injury can cause airway obstruction, mucosal sloughing, bronchorrhoea and pulmonary oedema. Presence of progressive hoarseness or stridor appearing 2 hours after inhalation, associated with deteriorating consciousness, needs careful evaluation and follow up. Burns of the tongue are most hazardous and tissue edema could be aggravated further by administration of large volumes of intravenous fluids for large surface-area burns. Oxygen therapy and airway management by endotracheal intubation, emergency tracheostomy or cricothyroidotomy accomplished expeditiously and as atraumatically as possible will be life saving. (8)

\section{Toxic products of combustion}

\section{Substance burned}

Wood, cotton, paper

Petroleum products

Melamine resins

Nitrocellulose film

\section{Toxic products}

Acrolein, acetaldehyde, formaldehyde, acetic acid, formic acid

Acrolein, acetic acid, formic acid

Ammonia, hydrogen cyanide

Oxides of nitrogen, acetic acid, formic acid 
Polyvinyl chloride

Polyurethane

Polyfluorocarbons

Fire retarded material
Hydrogen chloride, phosgene, chlorine

Isocyanate, hydrogen cyanide

Octafluoroisobutylene

Fluorides, bromides, iodides and asbestos

\section{Inhalational Injuries}

Inhalational injury can occur from direct inhalation of flames, inhalation of hot air, steam, smoke, toxic gases or by aspiration. The larynx represents a natural barrier, shielding against noxious agents from outside. Burn injuries of lower airway are nearly always associated with upper respiratory involvement. The direct pathological sequelae include hyperaemia, exudation, oedema and necrosis of the affected mucous membranes.

From the clinical point of view, significant manifestations include reddening, swelling and blistering of the air passages. In the vicinity of the glottis, this may present an acute danger due to airway obstruction and asphyxiation. In the lower respiratory tract, intra alveolar and/or interstitial oedema can occur. Necrotic mucoparticles can cause atelectasis, progressing to infections (bronchopneumonia, interstitial pneumonia, pulmonary abscess) and acute respiratory failure, especially if the pulmonary situation is complicated by general burn injuries. Shock waves produce an inflammatory response. Interleukin 8 is released, causing mobilization of polymorphonuclear leukocytes (PMNs) into the systemic circulation. The release of proinflammatory cytokines induces the expression of the CD11b receptor complex on the PMN surface, leading to adhesion at the site of injury. Select free-radical scavengers and inhibitors of inflammatory pathways are promising in phase I animal trials. In addition, blast injury to the lungs causes levels of inducible nitric oxygen synthase (iNOS) to increase in the brain, causing brain injury. (9)

Pulmonary barotraumas often occurs in blast injured victims. The varying pressure of waves created by the blast and their propagation in air and fluid results in interfaces of mediums of varying densities often called the 'spalling effect'. The pulmonary membrane system represents the anatomically largest interface between air and tissue. Underwater pressure waves, say from torpedo detonation, results in pressure waves with less attenuation than an air blast because of low compressibility of fluids in comparison to air. This often affects other large parenchymatous organs of the body like the liver and spleen, in addition to the lung. The blast effect on the lungs is rupture of tissue and vessels, resulting in pneumothorax, haemothorax, subcutaneous emphysema, diffuse pulmonary contusions and respiratory failure.

\section{Clinical Management of blast victims}

Screen for radioactive contamination with a hand-held Geiger counter for any explosion that may involve radioactive material, including any explosion that may have been deliberately set; if radioactive material is detected, decontamination of personnel and equipment as well as notification of the receiving hospital is required. (10)

If the explosion occurred in an enclosed space or was accompanied by fire, test for carboxyhemoglobin $(\mathrm{HbCO})$, methemoglobinemia and electrolytes to assess acid/base status. Exposure to cyanide $(\mathrm{CN})$, a product of incomplete combustion of plastics, is difficult to measure directly. CN exposure often accompanies $\mathrm{CO}$ poisoning. Consider $\mathrm{CN}$ poisoning in patients exposed to combustion in an enclosed space who have an anion gap metabolic acidosis. Treatment for $\mathrm{CN}$ poisoning should be started for significantly ill patients while awaiting confirmatory test results. Sodium thiosulfate or hydroxocobalamin are safe and appropriate empiric therapies. $(11,12)$ 
Rapid assessment for signs of hypoxia like cyanosis, restlessness, irrelevant talk and falling oxygen saturations must be made. Do not miss evidence of tension pneumothorax like shock, signs of mediastinal shift and rapidly progressing dyspnea. Insert a needle into the pleural space at the 2nd intercostal space anteriorly and aspirate. If it is positive for air, insert a chest drain and connect to a water-seal drainage system. Assess the extent and degree of facial and chest burns and subcutaneous emphysema. (13)

Look for subcostal indrawing, chest wall deformities and flail movements. Chest is percussed to detect changes in air entry in both lungs to evaluate pneumo-haemothorax. Gentle laryngoscopic evaluation must be done to detect airway burns and a chest radiograph ordered to diagnose broken ribs, subcutaneous emphysema, mediastinal shift, haemo-pneumothorax and changes in diaphragm orientation or movements. (14)

The immediate cardiovascular response to pulmonary blast injury is a decrease in heart rate, stroke volume, and cardiac index. The normal reflex increase in systemic vascular resistance does not occur, so blood pressure falls. This effect occurs within seconds. If this response is not fatal, recovery usually occurs within 15 minutes to 3 hours. However, even nonlethal PBI can impair pulmonary performance for hours to days. $(15,16)$

Acute gas embolism (AGE), a form of pulmonary barotrauma, requires special attention. Air emboli most commonly occlude blood vessels in the brain or spinal cord. Resulting neurologic symptoms must be differentiated from the direct effect of trauma. (17)

High-flow oxygen should be administered to all patients with respiratory distress, abnormal findings on auscultation, and evidence of significant thoracic trauma. Serial arterial blood gas analysis will prompt the decision for artificial ventilation. This will often be merited in the presence of inspiratory stridor, progressive desaturation/ coma especially when associated with maxillofacial and /or cranio-cerebral trauma. Blast lung cases have the dual problem of parenchymal contusion impairing diffusion and parenchymal broncho-pleural fistulae affecting ventilation (leaks are in the vicinity of 15 to $20 \%$ of tidal volume). Insert a large diameter apical and basal pleural closed/water-seal drainage. This may often have to be done through a burn-injured chest wall surface. If patients circulatory condition does not improve after relief of tension pneumothorax or if the shock index is more than 1, suspect internal bleeding, concomitant abdominal trauma/limb fractures. Anticipate difficult intubation and ventilation. This is best done in a tertiary level trauma centre, so consider an urgent evacuation. Do not air evacuate victim without insertion of chest drains. Crash induction with ketamine and rocuronium and insertion of double lumen endotracheal tube is preferable. Apply PEEP judiciously. Consider inverse-ratio (duration of inspiration phase to that of the expiration phase $=4: 1$ ) ventilation to provide sufficient gas exchange and enable the fistula to closure spontaneously. Pressure Regulated Volume Control ( PRVC) mode is a definite choice with tidal volumes not exceeding $6 \mathrm{ml} / \mathrm{kg}$. Also order endoscopy with a flexible bronchoscope to detect bronchial rupture and mucosal hyperemia of segmental bronchi. Bronchial lavage can be performed to flush out necrotic mucosa and spray topical corticosteriods. Cover with broad spectrum third and fourth generation antibiotics. (18)

Hemodynamically unstable patients with significant trauma may benefit from early use of packed red blood cells (PRBC) and fresh frozen plasma (FFP) in a 1:1 ratio, as well as platelets. Also consider cryoprecipitate and recombinant factor VIIa. Administer blood transfusion if hemoglobin is less than 7 $\mathrm{g} / \mathrm{dl}$ or hematocrit below $30 \%$ or when indicated clinically and assess progress. Good ventilatory management, early circulatory volume correction with colloids, crystalloids and/or blood, together with prophylactic mannitol $30 \mathrm{ml} / \mathrm{h}$ to prevent multi organ dysfunction are the keystones to successful outcome. Consider bolus dose of methylprednisolone $3 \mathrm{mg} / \mathrm{kg}$. $(19,20)$ 
Focused Abdominal Sonography for Trauma (FAST) is a potentially useful tool for rapidly screening patients, especially in the setting of multiple seriously injured victims. A positive FAST examination in an unstable patient is an indication for surgical exploration of the abdomen in the operating room. A negative FAST examination is unreliable in the setting of penetrating trauma to the abdomen, flank, buttocks, or back, and it should be followed up with CT examination of the abdomen and pelvis. (21) If abdominal pain persists or vomiting develops, consider admitting the patient for observation. Intestinal hematoma may be difficult to detect in the ED.

White phosphorus (WP) burns require unique management. Initial management of WP-contaminated burns consists of copious lavage of the area, removing identifiable particles (which should be placed in water to prevent further combustion), and covering the area with saline-soaked gauze to prevent further combustion. Use of a Wood lamp in a darkened resuscitation suite or operating room may help identify WP particles in the wound. Definitive treatment consists of a rinse using $1 \%$ copper sulfate $\left(\mathrm{CuSO}_{4}\right)$ solution and removing the WP particles. Copper sulfate combines with phosphorous particles to create a blue-black cupric phosphide coating. This impedes further WP combustion and makes particles easier to find. Rinse the contaminated burn with copper sulfate solution, remove WP particles, and then use copious saline lavage to rinse off the copper sulfate. Never apply copper sulfate as a dressing. Excess copper sulfate absorption can cause intravascular hemolysis and renal failure. WP injury can lead to hypokalemia and hyperphosphatema with ECG changes, cardiac arrhythmias, and death. Place the patient on a cardiac monitor and closely track serum calcium levels. Intravenous (IV) calcium may be required. Moistened face masks and good ventilation help protect patients and medical personnel from the pulmonary effects of phosphorous pentoxide gas. Naturally, avoid the use of flammable anesthetic agents and excessive oxygen around WP. (22)

\section{$\underline{\text { Mortality/Morbidity }}$}

Immediate death/injury rates were higher for bombings involving structural collapse (25\%) than for confined space (8\%) and open air detonations (4\%). (23) Enclosed-space explosions, including those occurring in buses, and in-water explosions produce more primary blast injury. Blasts in ultra-confined spaces such as buses have the highest associated mortality.(24) Explosions leading to structure collapse produce more orthopedic injuries. Land mine injuries are associated with a high risk of below- and abovethe-knee amputations. Fireworks-related injuries are higher in children, boys outnumbering girls 3:1 and involve mostly the eye or hand. $(25,26)$

Incidence of tympanic membrane rupture is in the vicinity of $30 \%$. TM perforation was noted to be poorly sensitive as a biomarker for more serious primary blast injury with only $50 \%$ of patients with serious PBI demonstrated TM rupture. (27) A majority of victims (approximately 70 percent) will sustain soft tissue injury and traumatic amputations will occur in approximately 11 percent of the cases. Up to $10 \%$ of all blast survivors have significant eye injuries. Pulmonary barotrauma is the most common fatal primary blast injury. This includes pulmonary contusion, systemic air embolism, and free radical-associated injuries such as thrombosis, lipoxygenation, and disseminated intravascular coagulation(DIC). ARDS may be a result of direct lung injury or of shock from other body injuries. Mild traumatic brain injury (mTBI) from primary blast forces may have greater post-concussive sequelae than mTBI from blunt forces. Severe head injury is the most common cause of death. Hemorrhage following severe lower limb trauma, often in conjunction with abdominal and pelvic injuries also has high mortality. (28) 


\section{REFERENCES:}

1. Wolf SJ, Bebarta VS, Bonnett CJ et al. Blast Injuries. Lancet. 2009;374:405-415.

2. Owen-Smith MS, editor. Hunterian lecture 1980: A computerized data retrieval system for the wounds for war: The Northern Ireland casualties. Journal of the Royal Army Medical Corps. 1981;127(1):31-54.

3. Mathews ZR, Koyfman A. Blast Injuries. J Emerg Med. 2015; 49 (4):573-87.

4. Champion HR, Holcomb JB, Young LA. Injuries from explosions: physics, biophysics, pathology, and required research focus. J Trauma. 2009; 66(5):1468-77.

5. Wolf SJ, Bebarta VS, Bonnett CJ, Pons PT, Cantrill SV. Blast injuries. Lancet. 2009 Aug 1. 374(9687):405-15.

6. Garth RJ. Blast injury of the ear: an overview and guide to management. Injury. 1995; 26(6):363-6.

7. Mayorga MA. The pathology of primary blast overpressure injury. Toxicology. 1997; 121(1):17-28.

8. Mackenzie IMJ, Tunnicliffe B. Blast injuries to the lung: epidemiology and management. Philos Trans R Soc Lond B Biol Sci. 2011; 366(1562): 295-299.

9. Gorbunov NV, McFaul SJ, Van Albert S, et al. Assessment of inflammatory response and sequestration of blood iron transferrin complexes in a rat model of lung injury resulting from exposure to low-frequency shock waves. Crit Care Med. 2004; 32(4):1028-34.

10. Flynn DF, Goans RE. Nuclear terrorism: triage and medical management of radiation and combined-injury casualties. Surgical Clinics of North America, 2006;86(3):601-636

11. Badii F, Maghelli S, Costa N, Borreggine D, Zoccali G, Durì D. Acute methemoglobinemia after nitroglycerine transcutaneous absorption after bomb explosion: a case report. J Trauma. 2009; 66(3):936-7

12. Jones J, McMullen MJ, Dougherty J. Toxic smoke inhalation: cyanide poisoning in fire victims. Am J Emerg Med. 1987;5(4):317-21.

13. Bass CR, Rafaels KA, Salzar RS. Pulmonary injury risk assessment for short-duration blasts. J Trauma. 2008.65(3):604-15.

14. Eastridge BJ, Blackbourne L, Wade CE, Holcomb JB. Radiologic diagnosis of explosion casualties. Am J Disaster Med. 2008 ;3(5):301-5

15. Guy RJ, Kirkman E, Watkins PE, Cooper GJ. Physiologic responses to primary blast. J Trauma. $1998 ; 45(6): 983-7$

16. Irwin RJ, Lerner MR, Bealer JF, et al. Cardiopulmonary physiology of primary blast injury. $\mathrm{J}$ Trauma. 1997; 43(4):650-5

17. Saada M, Goarin JP, Riou B et al. Systemic gas embolism complicating pulmonary contusion. Diagnosis and management using transesophageal echocardiography. Am J Resp Critical Care Med.1995; 152( 2): 812-5.

18. Dries DJ and Endorf WE. Inhalation injury: epidemiology, pathology, treatment strategies. Scand J of Trauma, Resusc and Emerg Med. 2013;21:31

19. Argyros GJ. Management of primary blast injury. Toxicology. 1997; 121(1):105-15

20. Ritenour AE, Baskin TW. Primary blast injury: update on diagnosis and treatment. Crit Care Med. 2008; 36(7):311-7

21. Tsui CL, Fung HT, Chung KL, Kam CW. Focused abdominal sonography for trauma in the emergency department for blunt abdominal trauma. Int J Emerg Med. 2008; 1(3): 183-187.

22. Chou TD, Lee TW, et al. The management of white phosphorus burns. Burns. 2001;27(5):492-7. 
23. Arnold JL, Halpern P, Tsai MC, Smithline H. Mass casualty terrorist bombings: a comparison of outcomes by bombing type. Ann Emerg Med. 2004; 43(2):263-73

24 Kashuk JL, Halperin P, Caspi G, Colwell C, Moore EE. Bomb explosions in acts of terrorism: evil creativity challenges our trauma systems. J Am Coll Surg. 2009;209(1):134-40

24. Moore JX, McGwin G Jr, Griffin RL. The epidemiology of firework-related injuries in the United States: 2000-2010. Injury. 2014; 45 (11):1704-9. .

25. Canner JK, Haider AH, Selvarajah S, Hui X, Wang H, Efron DT, et al. US emergency department visits for fireworks injuries, 2006-2010. J Surg Res. 2014; 190 (1):305-11

26. Harrison CD, Bebarta VS, Grant GA. Tympanic membrane perforation after combat blast exposure in Iraq: a poor biomarker of primary blast injury. J Trauma. 2009; 67(1):210-1.

27. Mendez MF, Owens EM, Reza G, et al. Mild traumatic brain injury from primary blast vs. blunt forces: Post-concussion consequences and functional neuroimaging. NeuroRehab. 2013;32(2):397407.

28. Keene DD, Penn-Barwell JG, Wood PR, Hunt N, Delaney R, Clasper J, et al. Died of wounds: a $\begin{array}{lllllll}\text { mortality } & \text { review. J } & \text { R } & \text { Army } & \text { Med } & \text { Corps. } 2015 & \text { Oct }\end{array}$ 